\title{
ASTHMA
}

\section{A 10 year asthma programme in Finland: major change for the better}

\author{
T Haahtela, L E Tuomisto, A Pietinalho, T Klaukka, M Erhola, M Kaila, M M Nieminen, E Kontula, \\ L A Laitinen
}

Thorax 2006;61:663-670. doi: 10.1136/thx.2005.055699

See end of article for authors' affiliations

......................

Correspondence to: Dr T Haahtela, Skin and Allergy Hospital, Helsinki University Central Hospital, P O Box 160, FIN-00029 HUS, Finland; tari.haahtela@hus.fi

Received

22 November 2005

Accepted 23 March 2006
Background: A National Asthma Programme was undertaken in Finland from 1994 to 2004 to improve asthma care and prevent an increase in costs. The main goal was to lessen the burden of asthma to individuals and society.

Methods: The action programme focused on implementation of new knowledge, especially for primary care. The main premise underpinning the campaign was that asthma is an inflammatory disease and requires anti-inflammatory treatment from the outset. The key for implementation was an effective network of asthma-responsible professionals and development of a post hoc evaluation strategy. In 1997 Finnish pharmacies were included in the Pharmacy Programme and in 2002 a Childhood Asthma miniProgramme was launched.

Results: The incidence of asthma is still increasing, but the burden of asthma has decreased considerably. The number of hospital days has fallen by 54\% from 110000 in 1993 to 51000 in 2003, 69\% in relation to the number of asthmatics ( $n=135363$ and 207757 , respectively), with the trend still downwards. In 1993, 7212 patients of working age (9\% of 80133 asthmatics) received a disability pension from the Social Insurance Institution compared with 1741 in 2003 (1.5\% of 116067 asthmatics). The absolute decrease was $76 \%$, and $83 \%$ in relation to the number of asthmatics. The increase in the cost of asthma (compensation for disability, drugs, hospital care, and outpatient doctor visits) ended: in 1993 the costs were $€ 218$ million which had fallen to $€ 213.5$ million in 2003 . Costs per patient per year have decreased $36 \%$ (from $€ 1611$ to $€ 1031$ ).

Conclusion: It is possible to reduce the morbidity of asthma and its impact on individuals as well as on society. Improvements would have taken place without the programme, but not of this magnitude.
$\mathrm{T}$ he last 10 years have been a golden period for asthma guidelines, both internationally and nationally. ${ }^{1-11}$ These guidelines aim at improving the standard of asthma care, but the current level of asthma control still falls short of published guidelines, even in Europe. ${ }^{12}{ }^{13}$ The key question has been implementation of the best practice at the various levels of health care. Successful management depends on promoting adherence of both healthcare providers and patients to treatment. ${ }^{14} 15$

In the early 1990s the Ministry of Social Affairs and Health in Finland (population 5.2 million) recognised asthma as an important public health issue and set up a national programme lasting from 1994 to 2004 to improve asthma care and limit the projected increases in costs. ${ }^{16}$ The Finnish programme is comprehensive and reaches deep into the structures of health care. The first results of the programme were reported at the end of 2000. ${ }^{17}$ The present paper summarises the results of the whole programme period from 1994 to 2004

\section{METHODS}

\section{Working strategy and implementation}

The steering committee of the programme set goals and measures, and planned activities both for adults and children. ${ }^{16}$ The main goal of the 10 year programme was to lessen the burden of asthma on individuals and society. Measures to achieve the goals were as follows:

- early diagnosis and active treatment;

- guided self-management as the primary form of treatment;
- reduction in respiratory irritants such as smoking and environmental tobacco smoke;

- implementation of patient education and rehabilitation combined with normal treatment, planned individually and timed appropriately;

- increase in knowledge about asthma in key groups; and

- promotion of scientific research.

The programme was run by the Finnish Lung Health Association (Filha), a non-governmental organisation (expert NGO, www.filha.fi) and employed one pulmonologist. Overall, the direct extra cost of the programme was $€ 0.65$ million including $€ 125000$ from the Ministry of Social Affairs and Health who gave their political commitment to

Table 1 Stepwise educational sessions and target groups during the 10 year programme organized by Finnish Lung Health Association (Filha) and other professional bodies

\begin{tabular}{llc}
\hline Step & $\begin{array}{l}\text { No of } \\
\text { sessions }\end{array}$ & $\begin{array}{l}\text { No of } \\
\text { participants }\end{array}$ \\
\hline $\begin{array}{l}\text { (1) Pulmonary and paediatric } \\
\text { hospital units }\end{array}$ & 100 & 5300 \\
$\begin{array}{l}\text { (2) Primary and secondary care } \\
\text { professionals }\end{array}$ & 237 & 3700 \\
$\begin{array}{l}\text { (3) All healthcare professionals } \\
\text { (4) Regional paediatricians and } \\
\text { primary care professionals } \\
\text { (mini-programme) }\end{array}$ & 450 & 25500 \\
& 25 & 1300 \\
\hline
\end{tabular}


Table 2 Facilities and knowledge of asthma care in Finnish health centres in $2000^{20}$

\begin{tabular}{ll}
\hline Facility/knowledge & $\begin{array}{l}\text { Proportion of } \\
\text { health centres } \\
(\%)\end{array}$ \\
\hline $\begin{array}{l}\text { Peak flow meters available } \\
\text { Guided self-management used }\end{array}$ & 100 \\
Inhaled corticosteroid as first line & 98 \\
medication & 97 \\
Spirometry available & 95 \\
Local asthma-responsible person designated & \\
$\quad$ Nurse & 94 \\
$\quad$ General practitioner & 83 \\
Regional asthma programme available & 79 \\
Diagnosis of adult asthma in health centre & 77 \\
At least annual follow up visit & 75 \\
recommended & 71 \\
Asthma education arranged for & \\
professionals (mean 3.2 sessions/centre & \\
in 2 years) & \\
\hline & \\
\hline
\end{tabular}

the programme. The intervention was managed by integrating the tasks into the everyday practice of healthcare staff. Most of the activities were part of the clinicians' and administrators' routine work.

The programme obtained broad commitment from Finnish health care. For instance, a 1998 survey of chief physicians showed that $90 \%$ had changed their asthma practices in their clinics based on the programme. ${ }^{17}$ International adherence of doctors to the guidelines has been considerably lower. ${ }^{14}$ of the 21 Finnish hospital districts, 65\% have also launched regional programmes.

The key to implementation has been the network of local asthma coordinators (one physician and at least one nurse) in each Finnish healthcare centre $(n=271)$. Two hundred local asthma-responsible physicians and 580 asthma-responsible nurses currently ensure the quality and continuity of asthma management in primary health care. Specialists in hospital based pulmonary and paediatric units have been responsible for regional cooperation, including developing and updating the referral and treatment network and regional guidelines.

The programme has been enlarged twice. In 1997 nearly all Finnish pharmacies were included in the Pharmacy Programme. The Association of Finnish Pharmacies created a network of 695 asthma pharmacists in local pharmacies and started their continuous training. In 2002 a Childhood Asthma mini-Programme was launched. This consisted of practical checklists including (1) a good referral letter to a specialist, (2) a reply letter from the specialist to the general practitioners (GPs) and to the parents, (3) a structure for follow up visits, and (4) a self-management form to be individualised for each patient. Asthmatic children had been almost exclusively under the care of paediatricians, but the role of GPs and primary care had to be strengthened.

\section{Regional education}

There were four main educational steps. All State Provincial Offices were informed of the objectives of the programme and Filha organized (together with hospital pulmonary and paediatric specialist units) half-day educational sessions. The regional specialist units in turn invited the local primary care coordinators to attend these sessions (table 1).

Patient organisations (NGOs: the Allergy and Asthma Federation and the Pulmonary Association HELI) have had a major impact in direct patient counselling and distributing free of charge booklets, videos, and CD-ROMS concerning asthma, allergy, smoking, indoor air quality, and ambient air pollution. Patient organisations and pharmaceutical companies have financially supported a major part of the educational activities but had to follow the general principles of treatment strategies and self-management guidelines set up for the programme. ${ }^{16-18}$

A summary of the activities of the Finnish asthma programme from 1994 to 2004 is shown in the online supplement available at http://www.thoraxjnl.com/supplemental.

\section{RESULTS}

\section{Primary care}

Primary care chief physicians in northern Finland $(\mathrm{n}=58$, response rate $78 \%$ ) were surveyed by questionnaire in $2000 .{ }^{19}$ They reported that knowledge and facilities to examine asthma patients were good in $84 \%$ of the healthcare centres; $70 \%$ of the centres had arranged asthma education staff meetings during the previous 2 years. A regional asthma physician acted mainly as a consultant to other GPs and coordinated the work with regional specialists. Asthma nurses gave most of the patient education and served as contacts for patients.

During 2000 and 2001 the asthma coordinating physicians $(n=248)$ were interviewed regarding their facilities and knowledge in $91 \%$ of the health centres. ${ }^{20}$ The organisation and resources for asthma care were well established (table 2). Asthma nurses were surveyed with regard to their practices in $2004(\mathrm{n}=431$, response rate $73 \%)$. In $92 \%$ of the health centres patients were recommended to visit an asthma nurse after a scheduled physician visit, and this was an organised activity in $56 \%$ of the health centres (A Pietinalho, personal communication, 2005).

\section{Communication between primary and specialist care} In 2004 regional adult asthma guidelines were available in $79 \%$ of the 21 hospital districts (in $52 \%$ also on their websites); $48 \%$ also had regional guidelines for children on their websites. For example, in Hyvinkää, a southern Finland hospital district (population 160 000), the regional guidelines were launched in 1998. The results of the implementation were evaluated before the launch (in 1997, 366 patients) and after (in 1999, 280 patients). ${ }^{21}$ A major change occurred towards better use of specialist services. Asthmatics stayed in specialist care for shorter periods (2.3 years before, 1.3 years after) and specialists took care of those with more severe asthma. Guided self-management was used more often (36\% $v 46 \%)$ and patient satisfaction had risen from $65 \%$ to $75 \%$.

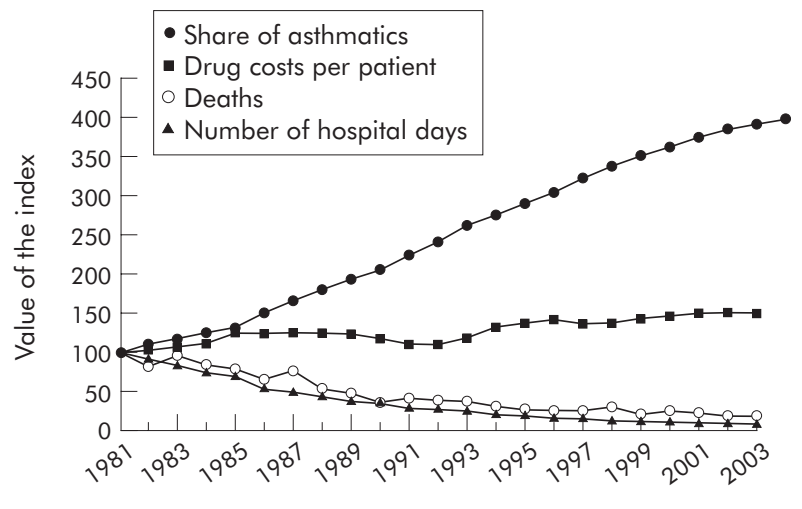

Finnish Asthma Programme 2005

Figure 1 Increase in number of asthmatic patients entitled to special reimbursement for their drug costs, increase in drug costs per patient, decrease in death rate, and decrease in hospital days due to asthma. Numbers are relative changes after 1981 (index, 1981 = 100). 


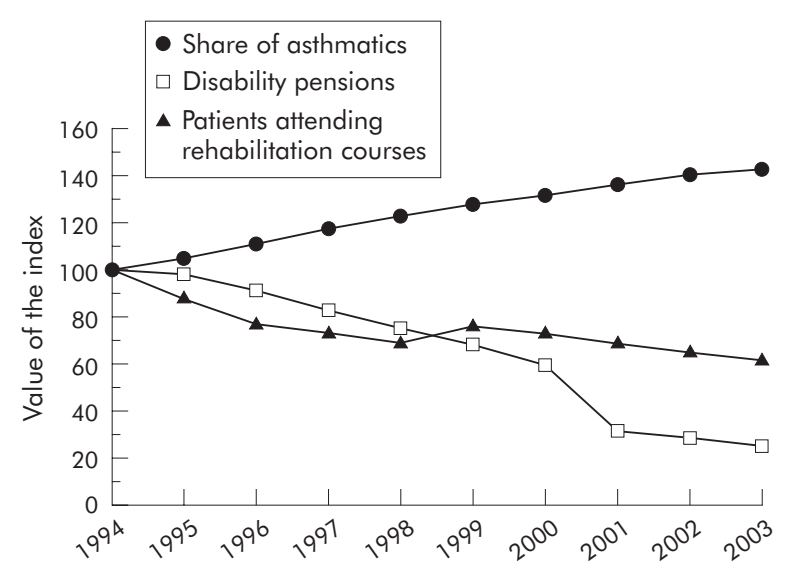

Figure 2 Increase in patients entitled to special reimbursement for their drug costs, decrease in patients on disability pensions, and decrease in patients attending rehabilitation courses for asthma. Numbers are relative changes after 1994 (index, 1994=100). Data from Social Insurance Institution.

Regular check-up visits also increased. In Southern Ostrobothnia (population 190000 ) 26\% of patients in 2000 and $48 \%$ in 2004 had made a check-up visit to their primary care physician during the previous year (L E Tuomisto, personal communication).

\section{Pharmacies}

The pharmacy programme has reached $94 \%$ of the Finnish pharmacies. In 2004 pharmacists provided patients with written or oral information on "preventers" and "relievers" during $98 \%$ of their purchases of asthma drugs. ${ }^{22}$ Instructions on inhalation technique was provided to $98 \%$ of new asthmatics, and to $34 \%$ of others. The inhalation technique was actually checked for $53 \%$ of new asthmatics and for $12 \%$ of the others.

In the pharmacy surveys, in 1998 less than $80 \%$ of patients purchasing asthma drugs reported that they had their "own" asthma doctor, but in 2004 this proportion was as high as $95 \%{ }^{23}$ Responsibility for care had been shifted to primary care, which was one of the main aims of the programme: $73 \%$ of adult asthmatics in 2000 had a GP as their asthma doctor; the figure was still low (17\%) for children. ${ }^{24} 25$

\section{Hospital admissions}

The number of hospitalisation days began to decrease before implementation of the programme, but is still falling. In 1993, a year before the programme was launched, the number of hospitalisation days due to asthma was around

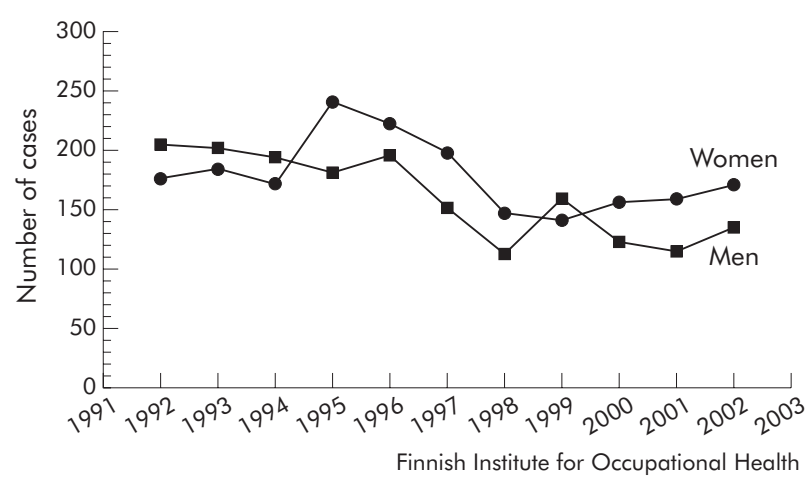

Figure 3 Registered cases of occupational asthma in Finland, 19922002.
110000 (271/100 000 patients). In 2003 this number had fallen to around 51000 (120/100 000 patients). The reduction in absolute figures was $54 \%$, and $69 \%$ in relation to the number of asthmatics.

For children, hospital admissions increased from 7.3 per 1000 in 1976 to 20.2 per 1000 in 1995. A remarkable 5.3-fold increase occurred in children aged $<5$ years $(2.6$ per 1000 in 1976, 13.8 per 1000 in 1995) ${ }^{26}$ After 1995 the admission rate turned downwards. In 1999 significant regional variation indicated differing practices for hospitalisations of children because of exacerbations. In the youngest age group hospitalisations varied from 3.1 to 7.4 per 1000 children). ${ }^{27}$

In 1981 the Finnish Social Insurance Institution (SII) recorded 49300 asthmatics entitled to special reimbursement for their drug costs. In 2004 this figure had increased fourfold to 212000 . In relation to the number of patients receiving special reimbursement-that is, the real at-risk populationthe number of hospital days in 2002 was only $10 \%$ of that in 1981 (fig 1). In comparison, hospital days due to chronic obstructive pulmonary disease (COPD) during the period from 1993 to 2003 increased by $5 \%{ }^{28}$

\section{Mortality}

The absolute number of deaths fell from 123 in 1993 to 85 in 2003 (fig 1). As a proportion of patients with registered asthma, the respective rates were $0.91 / 1000$ in 1993 and $0.41 /$ 1000 in 2003 . From 1976 to 2003 a total of 27 deaths occurred among those under 20 years of age, with only 10 between 1990 and 2003 (annual death rate 0-0.35/100 000).

\section{Emergency visits}

In Pirkanmaa hospital district (population 450 000), emergency visits due to asthma decreased in adults by $24 \%$ from 1995 to 2003 and by $61 \%$ in children (official registry of Tampere University Hospital).

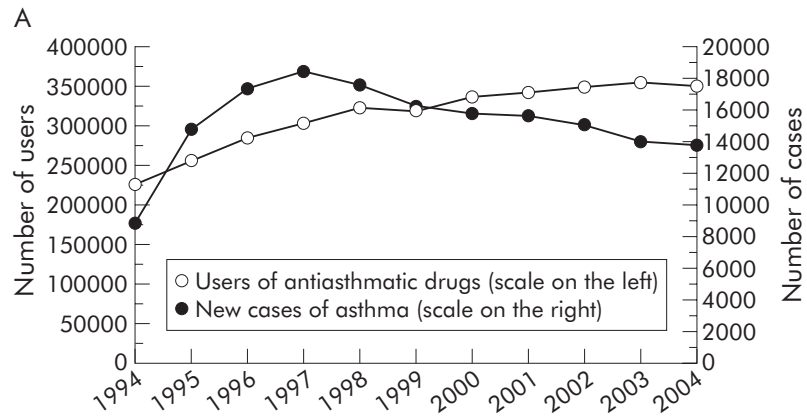

B

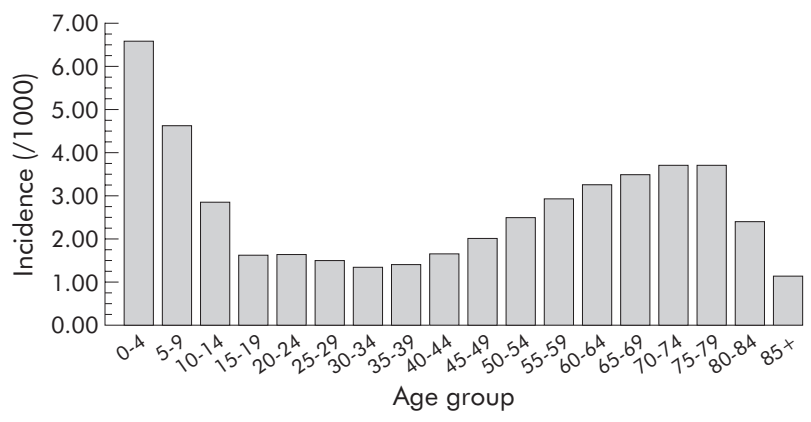

Figure 4 (A) Number of new patients entitled to special reimbursement for their drug costs from 1994 to 2004, and all users of anti-asthmatic drugs from 1994 to 2004 (not only those receiving special reimbursement for persistent disease). (B) Incidence of asthma patients (\%) according to the special reimbursement register in 2004 by age group. Data from Social Insurance Institution. 


\section{Disability and daily allowances}

In comparison with musculoskeletal or cardiovascular diseases or mental disorders, asthma is an uncommon cause for work disability. In 1993, 7212 patients of working age (9\% of all asthmatics) received disability pensions from the SII compared with 1741 in 2003 (1.5\%). The absolute decrease was $76 \%$ and, in relation to the number of asthmatics, $83 \%$ (fig 2).

Daily allowances paid by sickness insurance for asthma decreased by $27 \%$ from 1993 to 2003. Compensation was paid for 145200 lost days in 1994 (2966 sickness periods) and for 105700 days in 2003 (1920 sickness periods). The respective costs were $€ 5.2$ million in 1993 and $€ 3.9$ million in 2003. These figures include only those involving at least 10 day absences from work, those days for which allowances are paid.

\section{Rehabilitation}

Between the years 1994 and 2004, the number of patients attending adaptation training and rehabilitation courses for asthmatics organised by the SII (the major financer of rehabilitation) fell 57\%, from 2758 to 1181 (fig 2).

\section{Occupational asthma}

Finland has strict legislation for occupational diseases, and all verified cases are registered. The number of cases of occupational asthma decreased in the 10 year period from about 400 to 300 per year (fig 3). This favourable trend is largely due to the long term active work of the National Institute of Occupational Health. In a Finnish population based follow up study, the proportion of cases attributable to occupation among 50000 incident asthma cases was 29\% (95\% CI 25 to 33) for men and 17\% (95\% CI 15 to 19) for women, indicating that the effect of work is larger than generally assumed. ${ }^{29}$ No comparable data are available from other countries.

\section{Medication}

In 1987 a nationwide health survey showed that only one third of Finnish asthma patients used inhaled steroids. ${ }^{30} \mathrm{~A}$ major change has taken place since. Both in 2001 and 2004, over $85 \%$ of patients purchasing asthma drugs from pharmacies used inhaled steroids daily. ${ }^{23}$

According to SII registers, in 1993 the number of patients with asthma entitled to $75 \%$ reimbursement was around 135 500, of whom about 19000 (14\%) were children. In 2004 the total number was around 212000 (a 56\% increase), of whom $28500(13 \%)$ were children-a 50\% increase. The

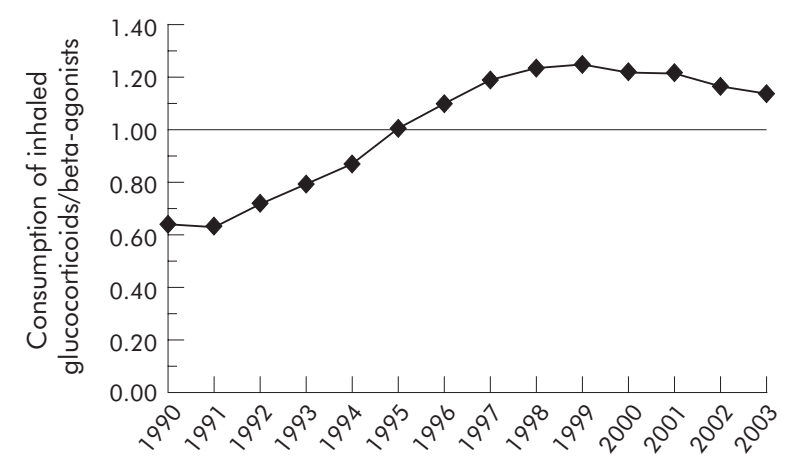

Figure 5 Ratio of consumption of inhaled corticosteroids and $\beta_{2}$ agonists from 1990 to 2003 in defined daily doses (ddd/ 1000 inhabitants/day). A combination of steroid and $\beta_{2}$ agonist was added to the prescriptions for both $\beta_{2}$ agonists and corticosteroids. Data from National Agency for Medicines.

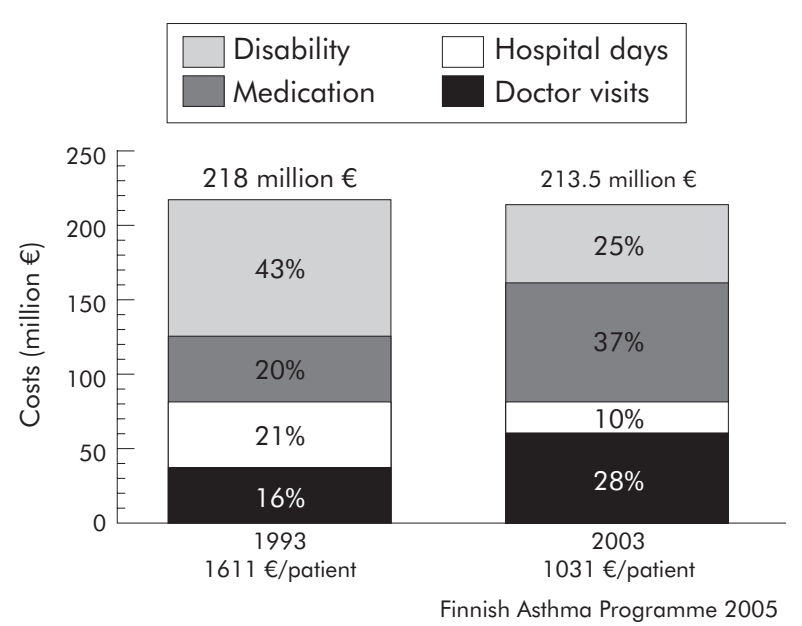

Figure 6 Direct annual costs of asthma (medication, hospital days, doctor visits) and compensation for disability pensions and days off work in Finland, 1993 and 2003. The gross national product in Finland was $€ 19809$ /inhabitant in 1993 and $€ 27585$ /inhabitant in 2003 (index year in all calculations 2003). Data from Social Insurance Institution.

number of registered new asthmatics increased steadily until 1997, since when it has been declining (fig 4A).

The age related incidence of new registered asthma cases shows two peaks: a high peak among small children and another smaller peak among the elderly (fig 4B). Both peaks are slightly confounded, the former by overdiagnosis of asthma in infants and the latter by patients with COPD which, in the older age groups, accounts for about $5 \%$ of all patients entitled to reimbursement.

In another SII register established in 1994, prescriptions of asthma drugs increased steadily in the 1990s, but this trend slowed in the early 2000s and turned downwards during more recent years (fig 4A).

In 1995, Finland was the first Nordic country to reach a ratio of 1.0 for defined daily doses (ddd) of inhaled corticosteroids to those of $\beta_{2}$ agonists (fig 5). The use of combination inhalation preparations (salmeterol/fluticasone and formoterol/budesonide) has grown rapidly which has caused an increased use of $\beta_{2}$ agonists, even among those with mild asthma. This ratio has therefore again been approaching 1.0. A shift was promoted from metered dose inhalers to dry powder inhalers because of the foreseen international ban against CFC (freon) propellants. In 1993 dry powder inhalers comprised $29 \%$ of the total number of inhalers sold compared with $84 \%$ in 2003.

Of the nearly 50 chronic diseases which entitle the patient to special reimbursement, asthma was the second highest at the end of 2004, with only hypertension ahead of it. In children, asthma was by far the most common disease.

\section{Smoking}

From 1994 to 2004, smoking among Finnish men (28-27\%) and women $(20 \%)$ remained essentially unchanged. ${ }^{31}$ Adolescents (age 14-18) smoked slightly more in 1996 $(24 \%)$ than in $2004(22 \%){ }^{32}$ Asthmatics smoked as much as others from 1997 to 1999 in the Hyvinkää region (22$24 \%) .^{21}$

In 1994 smoking was prohibited in all workplaces. The proportion of employees exposed to environmental tobacco smoke during working days decreased from $71 \%$ to $21 \%$ between 1994 and1998, and exposure to tobacco smoke for more than 4 hours a day from $33 \%$ to $3 \%{ }^{33}$

In a Finnish population based incident case-control study (521 cases, 932 controls) the risk for asthma was significantly 
Table 3 Changes in asthma management during the programme

\begin{tabular}{|c|c|c|}
\hline & 1993 & 2004 \\
\hline \multicolumn{3}{|l|}{ Primary care } \\
\hline General practitioner & $\begin{array}{l}\text { Asthma suspicion referred to specialist } \\
\text { without lung function tests } \\
\text { Infrequent follow up visits } \\
\text { Prescriptions renewed without check up }\end{array}$ & $\begin{array}{l}\text { Diagnosis of asthma by GP } \\
\text { Short specialist consultation as needed } \\
\text { Anti-inflammatory treatment started without } \\
\text { delay } \\
\text { Easy access to evidence based guidelines } \\
\text { and local treatment chains } \\
\text { Annual follow up visits }\end{array}$ \\
\hline Nurse & $\begin{array}{l}\text { Rarely spirometry measurements made } \\
\text { or peak flow values followed }\end{array}$ & $\begin{array}{l}\text { Daily spirometry measurements } \\
\text { Routine guidance in peak flow } \\
\text { measurement and use of inhalers } \\
\text { Patient centred asthma education with } \\
\text { written action plan } \\
\text { Annual follow up visits }\end{array}$ \\
\hline \multicolumn{3}{|l|}{ Specialist care } \\
\hline Adults & $\begin{array}{l}\text { Diagnosis of asthma } \\
\text { Most follow up visits } \\
\text { Emergency care }\end{array}$ & $\begin{array}{l}\text { Only a portion of new diagnoses } \\
\text { Follow up of severe cases only } \\
\text { Part of emergency care }\end{array}$ \\
\hline Children & $\begin{array}{l}\text { Diagnosis, treatment, follow up of all } \\
\text { childhood asthma } \\
\text { Inpatient treatment of acute asthma }\end{array}$ & $\begin{array}{l}\text { Diagnosis of childhood asthma } \\
\text { Treatment, follow up of preschool asthma } \\
\text { Inpatient treatment of acute asthma }\end{array}$ \\
\hline & 1997 & 2004 \\
\hline \multicolumn{3}{|l|}{ Pharmacies } \\
\hline Asthma coordinators & $\begin{array}{l}\text { No actively organised role in asthma } \\
\text { care }\end{array}$ & $\begin{array}{l}\text { Active guidance in use of preventers and } \\
\text { relievers; guidance in inhalation technique } \\
\text { Networking with local health care }\end{array}$ \\
\hline
\end{tabular}

higher both among current smokers (adjusted odds ratio (OR) 1.33) and ex-smokers (adjusted OR 1.49) than among non-smokers. ${ }^{34}$

\section{Costs}

Costs attributable to asthma in Finland have decreased despite the substantial increase in the number of asthmatics (fig 1). In 1993, the year before the launch of the programme, the total direct costs from asthma and work disability were around $€ 218$ million (€1611 per patient), these sums being corrected by the inflation rate (fig 6). Ten years later the total costs of $€ 213.5$ million had decreased $2 \%$, but costs per patient (€1031) had decreased as much as $36 \%$. We can only speculate on the increase in total costs without the programme. If the costs per patient in 2003 had been the same as in 1993, total costs would have amounted to $€ 341.5$ million (potential saving $€ 128$ million for 2003). Development in health care and improved treatment would, however, have saved some costs even without the programme.

In 1993, sales of anti-asthmatic medicines in outpatient care were $€ 44$ million ( $20 \%$ of total costs), but in 2003 this share almost doubled to $€ 79$ million (37\%). The annual cost of medication per patient with special reimbursement-that is, persistent asthma requiring regular treatment-was 1.8 times higher in 2003 than in 1993. This growth is causing concern and is mainly due to the increasing use of steroid $/ \beta_{2}$ agonist combination preparations. The change to dry powder inhalers has also increased costs.

\section{DISCUSSION}

\section{Did we achieve the goals?}

The programme was aimed for the period 1994-2004. The changes in asthma management are summarised in table 3. We have been able to lessen the burden of asthma considerably and halt the increase in cost. The worrying trends are still the high incidence of asthma and growing drug costs. The preset goals were achieved as follows.
Goal 1: Recovery of as many patients as possible with early asthma

The number of children and adults with new special reimbursement for drug costs reached a turning point in 2001 and is decreasing. The asthma epidemic in Finland is still ongoing ${ }^{35}$ but may have reached its peak, as has been suggested in some other Western countries. ${ }^{36}{ }^{37}$ Moreover, many patients who previously received entitlement to special reimbursement for a restricted period may no longer need it after successful initial treatment.

Goals 2 and 3: Patients should feel well and their abilities should correspond to those usual for their age. Decline in percentage of patients with severe and moderate asthma from $40 \%$ to $20 \%$

Several indicators show that the proportion of patients with severe complications has substantially decreased, as have physical limitations. The absolute numbers for hospitalisation days, disability pensions, allowances for days off work, and need for rehabilitation have all decreased $30-50 \%$ and, in relative terms, even more.

\section{Goal 4: Decrease in number of days hospitalised by $50 \%$}

The number of days hospitalised has fallen by $56 \%$ from 110000 in 1993 to 51000 in 2003, and in relation to the number of asthmatics by $70 \%$. The trend is still downwards.

\section{Goals 5: Reduction in annual costs per patient by $50 \%$}

When compensation for disability, drugs, hospital care, and outpatient doctor visits are taken into account, costs per patient have decreased $36 \%$ and, if related to the increase in gross national product, by $50 \%$.

\section{Lessons learned}

To tackle common diseases like asthma requires a multidisciplinary action programme. This programme should include an operational plan for implementation and follow 
up. Effective strategies involve multiple methods, decision support systems, and interactive education. ${ }^{38} \mathrm{~A}$ broad commitment by the healthcare system and society is mandatory and should be sought at an early stage. The Finnish Ministry of Social Affairs actively supported the programme and acknowledged that asthma can be effectively detected and treated early. ${ }^{39-41}$ The steering group should be small (not more than 710 people), but it should comprise state officials, key experts, nurses, pharmacists, and patient organisations. Political commitment must be confirmed also at the regional level: state officials organised, in cooperation with the expert NGO (Filha), interactive sessions with the regional pulmonary and paediatric units. The regional specialist groups created a network of contact persons in local health centres as well as regional treatment guidelines and referral chains. The essence of long term success is to keep alive the network of contact persons, GPs, nurses, and pharmacists.

As the programme shifted its focus from maintenance treatment to early detection and prevention of exacerbations, the pulmonologists and paediatricians had to rethink their practices in order to ensure functioning regional treatment chains. The patients usually first contact their health centres regarding symptoms.

The shift in care from specialist to primary health providers has taken place over the whole country. Children are still mostly cared for by paediatricians; specialist work has also improved. For example, in a middle sized Finnish hospital in 1994, 16\% of new asthma diagnoses were made during the first visit compared with $42 \%$ in 2001 (L E Tuomisto, personal communication).

Small clinical improvements have a significant impact. For example, instructing primary care staff how to use a 2 week peak expiratory flow follow up and when to try a course of an inhaled steroid energised their work considerably. Furthermore, systematic teaching of the use of spirometry has proved useful. These simple means have essentially improved case identification and early intervention. Comorbidities of asthma like rhinitis, as well as allergic factors causing disease persistence, have also been in the educational focus.

Asthma treatment is drug centred and the programme recommended a simple medication regimen ${ }^{16}$ which has since been slightly modified. In recent years the decrease in new asthma patients entering the special reimbursement register probably indicates earlier and more effective intervention resulting in less persistent disease.

When purchasing drugs, the asthma patient has an important contact with a pharmacist. Along with the pharmacy programme, asthma pharmacists began instructing patients in the use of preventers and relievers (noticing excess purchases of relievers) and on the inhalation technique. Peak expiratory flow measurements have also been a topic of instruction in some pharmacies. Pharmacists have been highly motivated to follow the new initiatives.

One important and evidence based strategic choice was guided self-management. ${ }^{42}$ In one district the use of guided self-management increased in 2 years from $36 \%$ to $46 \%$, accompanied by improved patient satisfaction. ${ }^{21}$

Approximately $70 \%$ of all asthma is mild and may require only intermittent drug treatment. ${ }^{43}$ However, in both mild and more severe asthma, guided self-management is essential in preventing prolonged symptoms and exacerbations. Understanding and partnership are more important than compliance. ${ }^{44}$ The essential principles in asthma medication for adults and school-aged children are shown in Appendix 1.

Childhood asthma requires special consideration and a mini-programme for children was included in 2002. An electronic, easy to fill in and print self-management form is serving as the written (and readable) action plan. The developed checklists for referral letter, diagnostic work, and follow up are helping in both primary and secondary care.

This kind of programme cannot be effective without organised follow up and feedback, but even these are not enough. A rigorous evaluation plan is necessary in every large development programme. This was not fully acknowledged in 1994 when the Finnish initiative was taken, and caused problems in assessing the true impact of the programme.

Financial resources are necessary to start up and monitor the programme, but the two key words for success are "motivate" and "organise". Once the local work starts, it has its own dynamic which spreads to other regions who do not want to perform less well.

\section{Focal points for the future}

- The role of asthma nurses should be strengthened and made more independent. Educated nurses could tend to most routine check ups.

- Guided self-management should be further encouraged and a written action plan demanded. An electronic asthma follow up sheet has recently been developed for nationwide use.

- Clinical work requires handy tools to detect and monitor the inflammatory component of asthma. One recent innovation is a portable device to measure exhaled nitric oxide.

- Asthma in children under the age of 5 is often difficult to diagnose and, for treatment, specific guidelines may also be necessary to avoid both undertreatment and overtreatment.

- Anti-smoking work is still essential among asthmatic subjects. National smoking cessation guidelines have recently been published. ${ }^{45}$

- The combination preparations of inhaled steroids $/ \beta_{2}$ agonists may have improved the overall asthma control slightly but at a high cost. They are therefore not recommended as first line drugs. ${ }^{18}$ The unnecessary increase in drug costs should be halted.

- The Finnish government promotes a common electronic database for all healthcare providers to be in action in 2008. In the asthma treatment chain this database would allow, for example, better identification of patients in need of emergency visits and monitoring of prescriptions in local pharmacies.

\section{ACKNOWLEDGEMENTS}

The authors thank Aarne Lahdensuo for his contribution to the programme and Olli-Pekka Ryynänen for his aid, and are deeply grateful to the late Kaj Koskela who acted as a chairman of the programme.

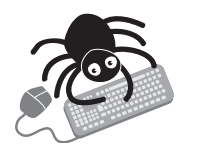

A summary of the activities of the Finnish asthma programme from 1994 to 2004 is shown in the online supplement available at http://www.thoraxjnl.com/ supplemental.

\footnotetext{
Authors' affiliations

T Haahtela, Skin and Allergy Hospital, Helsinki University Central Hospital, FIN-00029 HUS, Finland

L E Tuomisto, Department of Pulmonary Medicine, Seinäjoki Central Hospital, Huhtalantic 53, FIN-60220 Seinäjoki, Finland

A Pietinalho, E Kontula, Filha, Helsinki, Sibeliuksenkatu 11 Al, FIN00250 Helsinki, Finland

T Klaukka, Social Insurance Institution, Research Department, FIN00101 Helsinki, Finland
} 
M Erhola, The Municipal Joint Union for Public Health, FIN-13111 Hämeenlinna, Finland

M Kaila, Centre for General Practice, Pirkanmaa Hospital District, FIN33521 Tampere, Finland

M M Nieminen, Department of Respiratory Medicine, Tampere University Hospital, FIN-33521 Tampere, Finland

L A Laitinen, Department of Pulmonary Medicine, Helsinki University Central Hospital, FIN-00029 HUS, Finland

The Ministry of Social Affairs and Health and Finnish Lung Health Association (Filha) have supported this final report of the Asthma Programme.

Competing interests: none declared.

\section{REFERENCES}

1 NHLBI/WHO. Global strategy for asthma management and prevention. NHLBI/WHO Workshop Report, US National Heart, Lung and Blood Institute and the World Health Organisation, 1995.

2 National Institutes of Health (NIH). National asthma education and prevention program. Expert Panel Report 2: Guidelines for the diagnosis and management of asthma, NIH Publication No.97-4051. Bethesda, MD: National Institutes of Health, 1997.

3 North of England Asthma Guideline Development Group. North of England evidence based guidelines development project: summary version of evidence based guideline for the primary care management in adults. BMJ 1996;312:762-6.

4 National Institutes of Health (NIH). Global initiative for asthma. Global strategy for asthma management and prevention. Bethesda, MD: National Institutes of Health, 2004. Available at www.ginasthma.org

5 Dahl R, Bjermer L. Nordic consensus report on asthma management. Respir Med 2000;94:299-327.

6 Boulet LP, Becker A, Berube D, et al. Canadian Asthma Consensus Report 1999. Canadian Asthma Consensus Group. Can Med Assoc J 1999;161(Suppl 11):S1-61.

7 Bousquet J, van Cauwenberge P, Khaltev N, et al. Allergic Rhinitis and its Impact on Asthma. ARIA Workshop Report. J Allergy Clin Immunol Suppl 2001;108(5):S147-334.

8 New Zealand Guidelines Group. The diagnosis and treatment of adult asthma. 2002. Available at hitp://www.nzgg.org.nz.

9 National Asthma Council Australia. Asthma management handbook, Updated 2002. National Asthma Council Australia. Available at www.nationalasthma.org.au.

10 British Thoracic Society, Scottish Intercollegiate Guidelines Network. British guideline on the management of asthma. Thorax 2003;58(Suppl I): 1-94.

11 International Primary Care Airways Group (IPAG). Chronic airways disease. A guide for primary care physicians. IPAG diagnosis and management handbook, MCR Vision, 2005.

12 Rabe KF, Vermeire PA, Soriano JB, et al. Clinical management of asthma in 1999: the Asthma Insights and Reality in Europe (AIRE) study. Eur Respir J 2000;16:802-7.

13 Rabe KF, Adachi M, Lai CKW, et al. Worldwide severity and control of asthma in children and adults: the global Asthma Insight and Reality surveys. J Allergy Clin Immunol 2004:114:40-7.

14 Cerveri I, Locatelli F, Zoia MC, et al. International variations in asthma treatment compliance: the results of the European Community Respiratory Health Survey (ECRHS). Eur Respir J 1999;14:288-94.

15 World Health Organization. Adherence to long-term therapies: evidence for action. Geneva: World Health Organization, 2003:78.

16 Haahtela T, Laitinen LA. Asthma programme in Finland 1994-2004. Report of a Working Group. Clin Exp Allergy 1996;26:1-24.

17 Haahtela T, Klaukka T, Koskela K, et al. Asthma programme in Finland: a community problem needs community solutions. Thorax 2001;56:806-14.

18 Anon. Diagnosis and treatment of asthma, evidence based current care guideline (in Finnish). Duodecim 2000;116:2568-94 (updated 2006, in press).

19 Ikäheimo P, Tuuponen T, Hartikainen S, et al. Patients' low motivations makes problems in asthma management (in Finnish). Sosiaalivakuutus 2001;4:24-8.

20 Erhola M, Makinen R, Koskela K, et al. The Asthma Programme of Finland: an evaluation survey in primary health care. Int J Tuberc Lung Dis 2003:7:592-8.

21 Brander PE. Effect of regional asthma treatment chain on need for specialist care (in Finnish) Suom Lääkäril 2003;58:1803-10.

22 Peura S, Hirvonen A, Klaukka T. The first years of the Pharmacy Programme (in Finnish). Dosis 2004;20:147-51.

23 Klaukka T, Hirvonen A, Karhula K, et al. Good and bad news from asthma. Asthma barometer 2004 (in Finnish). Suom Lääkäril 2004;42:4002-4.

24 Kaila M, Pietinalho A, Vanto T, et al. The way childhood asthma is treated in Finland (in Finnish). Suom Lääkäril 2004:33:2937-9.

25 Ikäheimo P, Tuuponen T, Hartikainen S, et al. T. Achievements and shortcomings of Finnish asthma care. Scand J Public Health 2004;32:310-6.

26 Malmström K, Korhonen K, Kaila M, et al. Acute childhood asthma in Finland: a retrospective review of hospital admissions from 1976 to 1995. Pediatr Allergy Immunol 2000;1 1:236-40.

27 Valovirta E, Kocevar S, Kaila M, et al. Inpatient resource utilization in younger $(2-5)$ and older (6-14) asthmatic children in Finland. Eur Respir J 2002;20:1-6.
28 Säynäjäkangas $\mathrm{O}$, Lampela $P$, Pietinalho $A$, et al. National COPD programme half a way: changes in hospital use (in Finnish). Suom Lääkäril 2003;58:4729-32.

29 Karialainen A, Kurppa K, Martikainen R, et al. Work is related to a substantial portion of adult-onset asthma incidence in the Finnish population. Am J Respir Crit Care Med 2001; 164:565-8.

30 Peura S, Martikainen J, Klaukka T. Use and costs of asthma medication in 1980s (in Finnish, summary in English). Publication M: 72. Helsinki:Social Insurance Institution, 1990.

31 Helakorpi S, Patja K, Prättälä R, et al. Health and health behaviour of Finnish adults (in Finnish). Publication B13/2004. Finnish National Institute of Health, 2004.

32 Kouluterveystutkimus. School health study (in Finnish). Available at http:// www.stakes.fi/kouluterveys/ktpaivat/index.html.

33 Heloma A. Impact and implementation of the Finnish Tobacco Act in workplaces, People and Work Reports 57. Helsinki: Finnish Institute of Occupational Health, 2003.

34 Piipari R, Jaakkola JJK, Jaakkola N, et al. Smoking and asthma in adults. Eur Respir J 2004;24:734-9.

35 Latvala J, von Hertzen L, Lindholm H, et al. Trends in prevalence of asthma and allergy in Finnish young men: nationwide study, 1966-2003. BMJ 2005;330:1186-7.

36 von Hertzen L, Haahtela T. Signs of reversing trends in prevalence of asthma. Allergy 2005;60:283-92.

37 Zöllner IK, Weiland SK, Piechotowski I, et al. No increase in the prevalence of asthma, allergies, and atopic sensitisation among children in Germany: 1992-2001. Thorax 2005:60:545-8.

38 Grimshaw JM, Russell IT. Achieving health gain through clinical guidelines. II. Ensuring guidelines change medical practice. Qual Health Care 1995;3:45-52.

39 Laitinen LA, Heino M, Laitinen A, et al. Damage of the airway epithelium and bronchial reactivity in patients with asthma. Am Rev Respir Dis 1985:131:599-606

40 Haahtela $T$, Järvinen $M$, Kava $T$, et al. Comparison of a $\beta_{2}$-agonist, terbutaline, with an inhaled corticosteroid, budesonide in newly defected asthma. N Engl J Med 1991;325:388-92.

41 Haahtela T, Järvinen $\mathrm{M}$, Kava T, et al. Effects of reducing or discontinuing inhaled budesonide in patients with mild asthma. N Engl J Med 1994;331:700-5.

42 Lahdensuo A, Haahtela T, Herrala J, et al. Randomised comparison of self management and traditional treatment of asthma over one year. BMJ 1996:312:748-52.

43 Boushey HA, Sorkness CA, King TS, et al. Daily versus as-needed corticosteroids for mild persistent asthma. N Engl J Med 2005;352:1519-28.

44 Partridge MR, Fabbri LM, Chung KF. Delivering effective asthma care - how do we implement asthma guidelines? Eur Respir J 2000;15:235-7.

45 Finnish Association for General Practice. Guidelines for smoking, nicotine dependency and interventions for cessation (in Finnish), 2003. Available at http://www.kaypahoito.fi/pls/kh/kaypahoito? suositus = hoi50016.

\section{APPENDIX 1: ESSENTIAL PRINCIPLES IN ASTHMA MEDICATION FOR ADULTS AND SCHOOL-AGED CHILDREN}

Treatment is always tailored to patient needs. These principles have been slightly modified since $2001 .^{17}$

\section{Principle 1: Start effective anti-inflammatory treatment early, win the patients confidence, and improve the outcome}

- Get the disease under control with a moderate to high dose of inhaled steroid-for example, for 4 weeks. Adjust dose according to the need for a reliever, a rapid acting $\beta_{2}$ agonist.

- Step down dose to maintain the result, and further down to identify the lowest dose to control symptoms and maintain lung function.

- Check inhalation technique and treatment adherence if treatment is insufficient.

\section{Principle 2: Treat according to disease severity}

- Intermittent symptoms. Inhaled steroid, for example in 4 week courses, rapid acting $\beta_{2}$ agonist as needed.

- Mild, persistent symptoms. Inhaled steroid regularly, dose may vary. Rapid acting $\beta_{2}$ agonist as needed. Leukotriene modifier as a possible alternative to inhaled steroid, which is usually more effective.

- Moderate, persistent symptoms. Inhaled steroid and long acting $\beta_{2}$ agonist from two separate inhalers or from a single inhaler (combination preparation) regularly. Dosage 
can vary. Inflammation control can be improved by a leukotriene modifier or small dose theophylline, in which case a rapid acting $\beta_{2}$ agonist used only as needed.

- Severe, persistent symptoms. Add corticosteroid tablets in the morning to this regimen.

\section{Principle 3: Treat exacerbations early}

- Increase inhaled steroid dose 2-4-fold for 2 weeks. Use $\beta_{2}$ agonist regularly as well.

- With no improvement in 1-2 days, add corticosteroid tablets $20-40 \mathrm{mg}$ in the morning for 10 days.
- Prevent further exacerbations by adjusting regular treatment; give long acting $\beta_{2}$ agonist, leukotriene modifier, or small dose theophylline for longer periods of time.

\section{Principle 4: Educate the patient, provide a written self-management plan}

- If disease control is not optimal, guide the patient to use peak flow measurements at home.

- If symptoms increase and morning peak flow decreases by more than $30 \%$ or by more than $15 \%$ on two consecutive mornings, treat like an exacerbation.

\section{LUNG ALERT}

Is the time taken for sputum cultures to become negative in multidrug-resistant TB related to treatment outcome?

$\Delta$ Holtz TH, Sternberg M, Kammerer S, et al. Time to sputum culture conversion in multidrug-resistant tuberculosis: predictors and relationship to treatment outcome. Ann Intern Med 2006;144: 650-69

$\mathrm{P}$ eriodic sputum culture is used to monitor treatment efficacy in multidrug resistant tuberculosis (TB), and conversion of cultures from positive to negative for Mycobacterium tuberculosis is the most important indicator of progress. However, few studies have reported or evaluated sputum culture conversion status as an interim indicator of final treatment outcome. This study examined this and factors influencing the time to conversion.

This retrospective study looked at all patients with drug resistant TB identified from the Latvian national tuberculosis registry who began treatment with second line anti-TB drugs under the WHO DOTS-plus strategy in 2000 and who had positive sputum cultures at this time $(n=167) .77 \%$ of the cohort achieved sputum culture conversion, $23 \%$ did not. The median time to initial conversion was 83 days. Those who did not convert were more likely to have a previous history of treatment for multidrug resistant $\mathrm{TB}$, to have a history of incarceration, and to have resistance to a greater number of drugs at treatment initiation.

Univariate and multivariate regression analysis showed that previous treatment for multidrug resistant TB, bilateral cavitations on initial chest radiography, high colony count on initial sputum culture, and resistance to more drugs at the time of initiation were associated with a significantly longer time to initial sputum culture conversion. HIV status had no such predictive value. The median initial sputum culture conversion time was 48 days among those who were cured or completed treatment versus 169 days among those with a poor outcome (death, treatment default and treatment failure; $\mathrm{p}<0.001$ ). Conversely, a good treatment outcome was seen in $86 \%$ of those 129 who achieved sputum conversion within 60 days compared with $51 \%$ of those who did not do so within that period.

This study suggests that early sputum conversion is indeed a positive predictor of a successful outcome. These findings lend credence to the usefulness of monitoring sputum cultures as a means of assessing treatment efficacy and give rise to the possibility of identifying patients who might benefit from more aggressive intervention from the offset. The authors point out that limitations of their study include up to four missing sputum cultures in $75 \%$ of patients and, because of the nature of the study, the inability to count the actual number of days to sputum conversion as cultures were performed monthly.

F Morell-Ducos SHO in Medicine, Homerton University Hospital, London, UK; morellfausto@hotmail.com 